\title{
RELAÇÕES DE GÊNERO E RAÇA NO LIVRO $A$ INTRUSA DE JÚLIA LOPES DE ALMEIDA
}

\section{GENDER AND RACE RELATIONS IN JÚLIA LOPES DE ALMEIDA'S NOVEL $A$ INTRUSA}

Jhullya da Rosa Shalders ${ }^{1}$

Resumo: Este trabalho tem como finalidade analisar o romance $A$ Intrusa, de Júlia Lopes de Almeida, publicado primeiramente como folhetim em 1905 e depois como livro em 1908, inserindo-o no contexto político-social da época em que foi escrito e apresentando aspectos que fazem com que a autora e sua obra sejam pertinentes ao estudar o final do século XIX (época em que o romance é ambientado) e início do século XX. A relação entre história e literatura também será abordada, considerando que se pode observar aspectos históricos importantes do período no romance, como a construção de identidades, diferenças entre o público e o privado e questões de gênero e raça. Palavras-chave: Literatura; Júlia Lopes de Almeida; Gênero; Raça.

Abstract: This paper aims to analyze Júlia Lopes de Almeida's novel $A$ Intrusa, first published as a booklet in 1905 and later as a book in 1908, inserting it in the political-social context of the time it was written and presenting aspects about the author and her work that make them pertinent in studying the late nineteenth century (the time when the novel is set) and the early twentieth century. The relationship between history and literature will also be addressed, considering that important historical aspects of the period can be observed in the novel, such as the construction of identities, differences between public and private spheres, and gender and race issues.

Keywords: Literature; Júlia Lopes de Almeida; Gender; Race.

\footnotetext{
${ }^{1}$ Estudante do $7^{\circ}$ período do curso de História (Licenciatura e Bacharelado) na Universidade Federal do Paraná. Realiza pesquisa de Iniciação Científica sob a orientação da $\operatorname{Prof}^{a} \operatorname{Dr}^{\mathrm{a}}$ Ana Paula Vosne Martins.
} 


\section{Introdução}

Uma das vantagens de se estudar a categoria de gênero é sua fácil articulação com outras categorias, como classe e raça (LOURO, 1995). Ao analisar a literatura com esse viés, podemos estabelecer como as diferenças entre homens e mulheres são questões sociais e históricas, negando o determinismo biológico dessa relação. A literatura pode ser uma das fontes de um historiador, apesar de em uma primeira visão parecerem opostos. Em uma análise mais profunda, podem seguir caminhos próximos. As aleatoriedades e descontinuidades do tempo, que não são contempladas por uma História linear do progresso, podem ser observadas nos romances (HARTOG, 2017). Não se trata de necessariamente buscar acontecimentos históricos no romance, mas perceber à qual estrutura social o autor e seu público pertencem, seus valores e ideologias. $\mathrm{O}$ historiador deve estabelecer uma relação entre a sociedade e a obra de forma a encontrar a expressão do autor como sujeito histórico e a percepção dele acerca do seu próprio tempo.

Dessa forma, a análise histórica de um romance perpassa um estudo sobre a sua estética ao buscar compreender as condições culturais e sociopolíticas que levaram a sua escrita (FHILADELFIO, 2002: 134). É isto que faremos a seguir com o romance $A$ Intrusa, de Júlia Lopes de Almeida, publicado como livro em 1908.

Júlia Lopes de Almeida nasceu em 24 de setembro de 1862, no Rio de Janeiro, filha de pais portugueses. Em 1870, muda-se para a cidade de Campinas, em São Paulo, onde começa a escrever escondida dos pais. É incentivada à prática da escrita quando seu pai descobre seu segredo e, com apenas 19 anos, em 1881, passa a colaborar 
mensalmente com a Gazeta de Campinas $^{2}$. No ano de 1886 termina a parceria com o jornal, uma vez que se muda para Lisboa com a família.

Em Portugal, casa-se com o escritor naturalizado brasileiro Filinto de Almeida e os dois se mudam novamente para o Rio de Janeiro em 1888. Nessa época, Júlia já havia publicado algumas coletâneas e romances. Tem seu primeiro filho em 1888 e, um ano depois, a família mais uma vez se muda para a capital paulista. Foi em São Paulo que o prestígio de Júlia se consolidou.

Em 1895 retornam ao Rio de Janeiro, sendo Júlia já uma escritora consagrada. Na virada do século XIX para o XX, era considerada a escritora mais importante do Brasil. Parte disso se dava ao fato de Júlia conseguir conciliar a administração do lar com uma escrita de alto nível. A autora escreveu quase trinta livros, sendo que vários deles tiveram edições sucessivas.

Júlia escrevia em prosa em uma época na qual a maioria das escritoras brasileiras preferia a poesia, sendo o universo literário dominado pelos homens. Isso já mostra como a autora não se resignava aos papéis estabelecidos a partir das convenções de gênero, atuando para a modificação desses. Júlia organizou, em 1919, a Universidade Feminina Literária e Artística; em 1922, foi apontada como candidata para a representação no congresso feminista de Baltimore e, no mesmo ano, organizou, junto com Bertha Lutz, o primeiro Congresso Feminino do Brasil. Foi presidente honorária da Legião da Mulher Brasileira,

\footnotetext{
${ }^{2}$ Gazeta de Campinas foi um jornal que circulou na cidade de Campinas entre os anos de 1869 e 1875, tendo Campos Salles e Quirino dos Santos como principais redatores.
} 
criada em 1919, que tinha o objetivo de "amparar e elevar a mulher" (TELLES, 2012).

Júlia defendia uma melhor educação para o gênero feminino, mas fazia isso dentro dos valores burgueses de sua época. Escreveu livros pedagógicos, amplamente utilizados. Era a mulher mais publicada da Primeira República, mas foi esquecida depois de sua morte, em 1934. Leonora de Luca (1999: 277) defende que isso ocorreu devido ao equilíbrio da autora em relação à defesa dos costumes da época, ao mesmo tempo em que reivindicava certos direitos para as mulheres. Dessa forma, Luca cunha a expressão "feminismo possível" ao se referir a Júlia Lopes de Almeida.

Júlia sempre tentou e conseguiu conciliar a imagem de boa escritora, mãe e esposa presente, apontando como a mulher era subordinada, ignorante e despreparada para a vida; mas, ao mesmo tempo, expressava a importância da mulher no ambiente familiar, onde deveria servir ao marido e aos filhos. Os seus escritos mostram que acreditava que a mulher só se emanciparia por meio dos estudos e do trabalho (ELEUTÉRIO, 2005: 82).

Conciliava, desse modo, costumes e valores estabelecidos pelo patriarcado com ideais liberais e emancipatórios. Foi a única escritora do período que conseguiu se sustentar com o dinheiro de seu próprio trabalho (TELLES, 2004: 440). Assim, Júlia era considerada o modelo de mulher letrada a ser seguido durante toda a República Velha. Porém, a própria autora revelou que lia pouco e que gostaria de poder fazê-lo mais vezes. No entanto, era preciso cuidar dos filhos e da casa, fazendo 
com que não sobrasse tempo para se dedicar mais à leitura (RIO, 1992: $31)$.

Em 1896 publica o Livro das Noivas, considerado um manual a ser seguido para que as mulheres chegassem à perfeição e uma obra que ressaltava a importância da submissão feminina. Uma parte interessante dele a ser analisada é o fato de a autora afirmar que a mulher só conseguiria atingir a felicidade se tivesse criadagem na casa - pelo menos uma lavadeira, uma cozinheira, uma arrumadeira e uma babá. É importante lembrar que a abolição da escravidão ocorreu apenas oito anos antes da publicação do livro e que essas empregadas muito provavelmente seriam negras, realidade ainda vista nos dias de hoje.

Júlia estava presente nas primeiras reuniões de idealização da Academia Brasileira de Letras (ABL). Seu nome estava na primeira lista de fundadores da instituição, porém foi retirado - decidiu-se que esta seguiria o modelo da Academia Francesa, que não admitia mulheres. O nome do seu marido foi posto no seu lugar, como uma homenagem à autora. A ABL também instituiu o prêmio Júlia Lopes de Almeida para ficção escrita por mulheres, em forma de medalhão.

Outras obras importantes da autora são Memórias de Marta (1889), A Família Medeiros (1892), A Viúva Simões (1895) e A Falência (1901). Seu tema principal é a família burguesa no Segundo Império e na Primeira República.

O romance $A$ Intrusa foi lançado originalmente em folhetim no Jornal do Commercio ${ }^{3}$ (Rio de Janeiro), em 1905, sendo publicado

${ }^{3}$ Jornal do Commercio foi um jornal que circulou na cidade do Rio de Janeiro entre os anos de 1827 e 2016. Durante a monarquia, Dom Pedro II possuía uma coluna no jornal, que depois contou com nomes como Rui Barbosa e Lima 
como livro em 1908. Porém, sua história se passa na década de 90 do século anterior, na capital fluminense. A abolição da escravidão no país ainda era recente e a República tinha acabado de ser implantada. Esses dois acontecimentos são muito importantes para analisar a obra, assim como o papel da mulher na sociedade burguesa, podendo-se fazer a partir deste ponto, uma análise dos elementos que compõem as esferas do público e do privado.

A Intrusa conta a história de Argemiro, advogado abastado, que está à procura de uma governanta para administrar sua casa e cuidar de sua filha, Maria da Glória, nos dias em que ela o visitaria. Maria da Glória morava com seus avós maternos desde o falecimento de sua mãe. Argemiro coloca um anúncio no jornal, atitude criticada tanto por seus amigos, quanto pelos seus ex-sogros, e, assim, surge Alice. A nova governanta precisa seguir regras bastante exigentes, como nunca ficar no mesmo aposento que seu patrão. Isso faz com que Argemiro nunca sequer veja o rosto de Alice. A postura cuidadosa de Alice com a casa e com a pequena Maria da Glória encanta Argemiro, preocupando a sua ex-sogra, a baronesa Luiza. A presença de Alice gera muitos conflitos com todos ao redor de Argemiro, o que consistirá no enredo principal do romance.

\section{A influência das ideologias do século XIX no romance}

Segundo Paolo Rossi (2000), a teoria do progresso, ou seja, discursos sobre o crescimento e os avanços da ciência e da sociedade,

Barreto. No ano de sua extinção, era o jornal mais antigo ainda em circulação da América Latina. 
vai se articulando no final do século XVIII e atinge seu ápice no século XIX. A igualdade faz parte de tal progresso, sendo uma parte constitutiva da modernidade. Porém, ao mesmo tempo em que se afirma o valor da equidade, a contraideologia da desigualdade ainda está presente. Um exemplo disso é a escravidão nas Américas e, mesmo no pós-abolição, a crença em certa inferioridade das pessoas negras. Esse pressuposto é um traço marcante de A Intrusa de Júlia Lopes de Almeida.

Considerando que Júlia era muito lida em sua época, acredita-se que seu pensamento sobre as pessoas negras era compartilhado por grande parte da sociedade brasileira. A autora era abolicionista, vide seu romance pró-abolição, A Família Medeiros, mas era conservadora em relação ao papel que os negros ocupariam nessa nova formação da sociedade. A abolição da escravidão era recente quando o livro $A$ Intrusa foi publicado e os negros ainda eram vistos negativamente, sendo tidos como inferiores aos brancos, a exemplo do personagem Feliciano.

Feliciano trabalhava na casa de Argemiro desde quando sua esposa era viva. Quando ela morreu, o empregado ficou sem supervisão, pois Argemiro, homem de negócios, não tinha tempo para isso. A partir dessa nova situação, Feliciano se mostra desonesto, abusando de sua liberdade ao fumar os charutos do patrão e ao usar suas roupas:

Feliciano trouxe os charutos e Argemiro reconheceu que o negro se sortira abundantemente com os seus havanas. Sempre o mesmo abuso! Olhando com atenção para o criado, viu que ele ostentava cinicamente uma das suas 
camisas bordadas; também não estava certo de lhe haver dado já aquela bonita gravata roxa de bolinhas pardas (ALMEIDA, 2016, posição 478).

Argemiro já se mostrava descontente com Feliciano antes da chegada de Alice, mas é por meio do contraste com a figura da governanta que o caráter do criado vai ficar mais evidente, pois ele passa a perder seus privilégios. As comparações feitas pelo narrador deixam clara a diferença entre as pessoas brancas, boas, e as pessoas negras, ruins:

Havia um conforto novo, um aroma de malva ou de pomar florido, melhor luz, melhor ar, por aqueles compartimentos que o Feliciano, quando sozinho, enchia do cheiro dos cigarros e dos charutos (ALMEIDA, 2016, posição 1343). Ontem à noite recebi uma caderneta com a nota das despesas do mês e... pasma, saldo a meu favor! Eu não dizia que o Feliciano era um abismo? Que diferença! (ALMEIDA, 2016, posição 1364).

Depois que ela [Alice] está lá em casa nunca achei uma falta e nem uma traça na minha biblioteca! Antes, era um desespero! O Feliciano tinha aquilo em uma desordem... (ALMEIDA, 2016, posição 2923).

Argemiro justifica o mau caráter de Feliciano associando-o ao fato de que, quando criança, o empregado frequentara a escola, tendo acesso a uma educação formal, majoritariamente ocupada por pessoas brancas. Se tivesse tido uma formação adequada a sua negritude, não seria revoltado em relação a sua cor e a sua posição social. O ensino, que era direcionado para os brancos, deixou-o com má índole. Argemiro, em dado momento, afirma: 
- Meu sogro fez de um moleque humilde, um homem ruim... Se em vez de o mandar para a escola, com bolsa a tiracolo e sapatinhos de botões, o deixassem na modéstia da cozinha ou da estrebaria, ele não teria agora nem a revolta da sua cor nem a da sua posição... O que o torna mau é a inveja e a sua ignorância mal desbastada (ALMEIDA, 2016, posição 3000).

Acreditava-se que o negro possuía pouca inteligência e incapacidade para estudos mais aprofundados. Por isso, a miscigenação racial era vista negativamente para o futuro do Brasil e, portanto, somente com uma educação higienista o país poderia se modernizar e ir em direção ao progresso (MÜLLER, 2016). Algumas escolas brasileiras da Primeira República usavam a antropometria (mensuração do corpo humano ou de suas partes) para definir o biótipo de quem poderia frequentá-las; a raça era um importante fator para a diferenciação e hierarquização social nos ambientes escolares (ARANTES, 2016).

Percebe-se, então, a mentalidade da superioridade do branco em relação ao negro. O entendimento de Feliciano dessa situação o faz ter ódio dos brancos:

Revoltado contra a natureza que o fizera negro, [Feliciano] odiava o branco com o ódio da inveja, que é o mais perene. Criminava Deus pela diferença das raças. Um ente misericordioso não deveria ter feito de dois homens iguais dois seres dessemelhantes! (ALMEIDA, 2016, posição 2427).

A inveja de negros em relação aos brancos pode ser percebida em outras obras de Júlia, como em seu livro de contos Livros das donas e donzelas, publicado em 1906. Ao dedicar o livro para algumas de suas 
amigas, escreve: “Terá da negra Josefa, tão triste por não ser branca, a branca inocência" (ALMEIDA, 2012, posição 18).

Feliciano sempre mantinha pensamentos negativos em relação à Alice, inclusive várias vezes fantasiava seu assassinato: "O desejo do mal é silencioso. Oh, se ele [Feliciano] pudesse estender as unhas afiadas e fazer sangrar na escuridão a carne branca daquela mulher [Alice]!” (ALMEIDA, 2016, posição 2414). Por causa de seu ódio direcionado à governanta, Feliciano contava mentiras para a baronesa Luiza, fazendo com que ela se opusesse ainda mais à Alice, sendo esse um dos principais enredos do romance.

A narrativa evidencia o modo pelo qual as teorias científicas das desigualdades entre as raças humanas produzidas na Europa, como o Positivismo e o Darwinismo Social, influenciaram o Brasil. Segundo esta teoria, a raça negra era inferior à branca e, caso os negros ficassem a sua própria mercê, desapareceriam. Os negros, nesse sentido, seriam incapazes de criar ou fazer parte de uma civilização similar à europeia. Como a maioria da população brasileira era composta por negros retintos e negros de pele clara, o governo na época acreditava que o Brasil estava condenado a um atraso econômico, industrial e cultural.

\section{Outros aspectos do romance}

É importante considerar três aspectos do momento histórico do Brasil na época em que $A$ Intrusa foi escrito para analisá-lo: a recente abolição da escravidão, as influências europeias na cultura brasileira e a proclamação da República. Ser pró-abolição era uma característica comum aos republicanos, pois a burguesia, que estava em expansão no 
país, estava comprometida com o progresso e o desenvolvimento econômico.

Europeizar as cidades brasileiras também era um esforço desse novo sistema - buscava-se apagar as marcas coloniais do país a favor de um cientificismo como forma de seguir o caminho das cidades europeias. Um dos grandes temas da Júlia Lopes de Almeida era as cidades, principalmente o Rio de Janeiro. Várias de suas obras retratam a modernização da então capital do país no século XIX. No seu romance epistolar Correio da Roça, de 1909, Júlia enaltece o meio rural nessa época de urbanização ao fazer com que protagonistas acostumadas à cidade se encantem com a roça, mesmo que estivessem sendo obrigadas a se mudar. Um ponto curioso é que a autora era apaixonada por jardinagem, tendo escrito alguns livros sobre o tema, e defendia a conservação da Mata Atlântica carioca. Júlia pode ser considerada uma defensora do meio ambiente antes mesmo de o tema de preservação ambiental ser amplamente discutido.

Um exemplo da urbanização em $A$ Intrusa é em relação ao esporte:

- O esporte é a alma do Rio - afirmava a Pedrosa a uma amiga, no momento da aproximação de Adolfo. - Veja que entusiasmo! Decididamente, ele veio substituir os bailes... Hoje dança-se pouco. O remo e o futebol roubam os pares às moças... não é verdade, dr. Caldas? (ALMEIDA, 2016, posição 3408).

Porém, encarnado na personagem da baronesa Luiza, há a oposição a tudo o que é novo e moderno, incluindo a República: 
- Ah! Padre Assunção, a República estragou a nossa terra! Agora qualquer criatura parece digna de toda a confiança... Quem nos dirá quais as intenções daquela criatura? Por mim tenho medo, apesar da sua vigilância... (ALMEIDA, 2016, posição 1473).

A baronesa, junto com Feliciano, pode ser considerada a antagonista do romance. Presa a costumes e tradições passadas, ela resiste a uma educação mais moderna para sua neta, apegando-se ao fato de que Maria da Glória encontraria um marido bom e rico. É assim que Júlia Lopes de Almeida coloca seu ponto de vista sobre a educação feminina no livro:

- Ora, não digas isso! Ela [Maria da Glória] lê... e escreve... e demonstra muito jeito para a música. Afinal, não se educa para doutora nem para professora. No meu tempo não se exigia tanto...

- Não é razão. A mulher hoje precisa ser instruída, solidamente instruída, mamãe, e eu quero, eu exijo que minha filha o seja. [...]

- Glória casará bem, com um homem que a ame e a respeite. Não faltava mais nada! minha neta mal casada! pobre... desprezada... precisando trabalhar para viver... que coisa horrível!

- O que é horrível, mamãe, não é trabalhar; é não saber trabalhar! (ALMEIDA, 2016, posição 731-744).

A mulher perfeitamente educada se materializa na personagem da governanta, Alice. Sua história é um mistério durante todo o livro, sendo revelada apenas no final do romance. Alice era filha de um advogado que perde todo o seu dinheiro, falecendo logo em seguida. Ela estava estudando na França, pois sua mãe morreu quando jovem, mas, devido à morte do pai, precisa retornar ao Brasil. No seu país 
natal, vive na miséria, apesar de sua boa educação, junto com dois criados da família - um cego e uma paralítica. Mesmo com os dois sempre reclamando e se queixando de que ela fazia pouco por eles, trabalhava para sustentá-los, sem nunca reclamar.

Alice é o grande exemplo sobre o que Argemiro tinha avisado sua sogra no início do livro, quando ela reclama do anúncio no jornal. Porém, a profissão de governanta não se mostra como uma possibilidade de crescimento - a governanta sai da prisão dos pais para a do patrão, para servir sem ser vista. Mesmo assim, a esfera doméstica era considerada a mais apropriada para as mulheres:

Essa concepção dialogava com a ideia de que a presença feminina no espaço público precisava ser controlada, sob o risco de serem vítimas de malfeitores ou se tornarem mal faladas e prostituídas (GARZONI, 2014: 48-49).

No entanto, as mulheres do Rio de Janeiro, a partir de 1870, passam a compor a esfera pública, por conta da participação destas em jornais, por exemplo. Mas sempre era reforçada a importância de a mulher continuar na esfera privada, um ambiente considerado eminentemente feminino. Vemos isso em A Intrusa quando Argemiro sente a necessidade de ter uma mulher cuidando da sua casa e por isso contrata Alice - “Ah! uma casa sem mulher, afirmava ele, é um túmulo com janelas: toda a vida está lá fora...” (ALMEIDA, 2016, posição 124). Pode-se afirmar que o romance enaltece a dona de casa - Alice só se casa com Argemiro no final da história pois cuidou bem da residência e de Maria da Glória enquanto governanta. 
Para Habermas (1984: 64), a família burguesa é uma agência da sociedade, assumindo a função de mediar a aparência de liberdade e as exigências sociais. $\mathrm{O}$ casamento, que supostamente é uma vontade de ambos os cônjuges, muitas vezes pode ser relacionado a dinheiro e a posição - quando a família possui capital precisa tomar cuidado em relação à conservação e à multiplicação patrimonial. No romance, isso é exposto nas preocupações dos amigos de Argemiro quando ele resolve contratar uma governanta:

Todos eles suspeitavam das mulheres que prestavam serviços em casas de homens sozinhos, dizendo que elas seduziam os patrões para conseguir benefícios pecuniários. Assim, além de não serem bons exemplos de comportamento sexual e moral, ainda poderiam causar prejuízos (GARZONI, 2014: 46).

Percebe-se, então, que Júlia Lopes de Almeida pode ser incluída, nas palavras de Maria Angélica Lopes (1989: 54), no "feminismo patriarcal". Ou seja, o chefe de família é o homem, apesar da importância feminina, destacada na educação dos filhos. A mulher só deve sair dos bastidores quando não há um patriarca - uma situação indesejável - e assumir a chefia da família, com suas responsabilidades, mas não com os mesmos direitos.

A religião também está presente no livro, na imagem do melhor amigo de Argemiro, o Padre Assunção. Este não gosta de se envolver com aspectos políticos, pois a ambição dos homens não o faz bem, mesmo com toda a insistência de sua mãe, que nunca aceitou o fato de o filho ter escolhido ser padre. Para ela: 
O homem não nasce para o celibato, mas para a família; a missão ensinada por Deus é a do criador!. [...] Eu sou humana e amo a humanidade acima de tudo o mais! Não sei a que fonte foste buscar esse misticismo, que te isolou do mundo para que te criei (ALMEIDA, 2016, posição 3195-3230).

Assunção vira padre depois de uma desilusão amorosa e sua mãe nunca supera o fato de ele não ter se casado e tido filhos. Assim, podemos notar a importância que Júlia dá para a família, principalmente para os filhos - constituir uma família e procriar representariam a missão de todas as pessoas na terra; a castidade e a negação de ter uma família, mesmo que por motivos religiosos, não seriam noções naturais. Essa ideia pode ser encontrada em outras obras da escritora.

\section{Considerações finais}

Segundo Norma Telles (2004: 43), a cultura burguesa, a partir do século XVIII, fundamentava-se em binarismos como homem/mulher e natureza/cultura, que subjugam a mulher enquanto o outro, como natureza, sendo inferior ao homem, necessitando ser guiada pela cultura masculina. Júlia fazia objeção a isso, colocando sua imagem entre as margens do público e do privado - uma mulher que era esposa e mãe lutando por direito para as mulheres. Escrevia seus romances como um espelho da sua sociedade, colocando neles suas opiniões.

Mesmo assim, críticos da época, como Lúcio de Mendonça, comparavam sua escrita à de homens. Mendonça a considerava a escritora mais notável do momento, deixando isso claro no seu texto $A s$ três Júlias, de 1897, em que também mencionava as autoras Francisca 
Júlia e Júlia Cortines. Segundo ele, "só uma boa mãe de família" era capaz de ter escrito o Livro das Noivas. Mendonça também afirma que as três autoras trabalhadas em seu texto têm algo em comum e por isso são ilustres: "a índole máscula do seu talento". Ou seja, essas escritoras só escreviam bem pois possuíam uma varonilidade em seus escritos, que ainda assim não tirava a graça do sexo feminino ao escrever.

A mulher deveria cuidar da casa, porém a atividade intelectual, ao contrário do que se falava na época, não a faria menos feminina, nem lhe tiraria os encantos físicos. No entanto, com a problematização da questão racial, podemos concluir que o controverso feminismo da escritora não era para todas as mulheres, mas sim às brancas, ainda que pobres.

Ao usar obras literárias como fontes históricas, não se busca fazer uma restituição do passado, mas sim perceber quais eram os pensamentos das pessoas que viviam naquela época. A literatura é uma expressão coletiva historicamente datada (TELLES, 2012: 27). Fica evidente, dessa forma, que Júlia Lopes de Almeida foi influenciada por uma ideologia cientificista, que se refletia tanto na modernização da cidade do Rio de Janeiro como na crença de inferioridade do negro frente ao branco.

\section{Bibliografia}

ALMEIDA, Júlia Lopes de. Livros das Donas e Donzelas. Livro de Domínio Público, 2012. E-book.

ALMEIDA, Júlia Lopes de. A Intrusa. Editora Rastro Digital, 2016. E-book. 
ARANTES, Adlene Silva. Discursos sobre eugenia, higienismo e racialização nas escolas primárias pernambucanas (1918-1938). In: FONSECA, Marcus Vinícius; BARROS, Surya Aaronovich Pombo de (Orgs.). A história dos negros na educação no Brasil. Niterói: Eduff, 2016. p. 363-394.

DE LUCA, Leonora. O "feminismo possível" de Júlia Lopes de Almeida (1862-1934). Cadernos Pagu, Campinas, n. 12, p. 275-299, 2015.

$<$ https://periodicos.sbu.unicamp.br/ojs/index.php/cadpagu/article/view/8 634918>. Acesso em: 19 ago. 2019.

ELEUTÉRIO, Maria de Lourdes. Vidas de romance. Rio de Janeiro: Topbooks, 2005.

FHILADELFIO, Joana Alves. Lilith, Eva e Maria: mulher e mito na literatura. In: SANTOS, Luísa Cristina dos (Org.). Literatura e mulher: das linhas às entrelinhas. Ponta Grossa: Editora UEPG, 2002, p. 133-151.

GARZONI, Lerice de Castro. Feminismo e racismo no romance "A Intrusa" de Júlia Lopes de Almeida. Revista Grafia, Bogotá, v. 11, n. 1, p. 44-60, 2014. Disponível em: $<$ http://revistas.fuac.edu.co/index.php/grafia/article/view/507>. Acesso em: 19 ago. 2019.

HABERMAS, Juergen. Mudança estrutural na esfera pública. Rio de Janeiro: Tempo Brasileiro, 1984.

HARTOG, F. Do lado dos escritores: os tempos do romance. In: $\mathrm{Crer}$ em história. Belo Horizonte: Autêntica Editora, 2017.

LOPES, Maria Angélica. Júlia Lopes de Almeida e o trabalho feminino na burguesia. Luso-Brazilian Review, Wisconsin, v. 26, n. 1, p. 45-57, 1989. Disponível em: <https://www.jstor.org/stable/3513333?seq=1>. Acesso em: 19 ago. 2019.

LOURO, Guacira Lopes. Gênero, história e educação: construção e desconstrução. Educação e realidade, Porto Alegre, v. 20, n. 2, p. 101-132, jul./dez. 1994. Disponível em: 
$<$ https://seer.ufrgs.br/educacaoerealidade/article/view/71722/40669>. Acesso em: 19 ago. 2019. .

MÜLLER, Maria Lúcia Rodrigues. A produção de sentidos sobre mulheres negras e o branqueamento do magistério no Rio de Janeiro na Primeira República. In: FONSECA, Marcus Vinícius; BARROS, Surya Aaronovich Pombo de (Orgs.). A história dos negros na educação no Brasil. Niterói: Eduff, 2016, p. 395-412.

RIO, João do. A correspondência de uma estação de cura. São Paulo/Rio de Janeiro: Scipione/Fundação Casa de Rui Barbosa, 1992.

ROSSI, Paolo. De progressu verum cogitata et visa. In: Naufrágios sem espectador: A ideia de progresso. São Paulo: Unesp, 2000, p. 111-144.

TELLES, Norma. Encantações: escritoras e imaginação literária no Brasil - século XIX. São Paulo: Editora Intermeios, 2012.

TELLES, Norma. Escritoras, escritas, escrituras. In: PRIORE, Mary del (org.). História das mulheres no Brasil. São Paulo: Contexto, 2004, p. 401-442.

Recebido em: 19/08/2019

Aceito em: 12/09/2020 